\title{
Cianobacterias bentónicas marinas en el Caribe central y sur de Costa Rica
}

\section{Benthic marine cyanobacteria in the Caribbean and south Central Costa Rica}

\author{
Nelson Muñoz Simon ${ }^{1 *}$
}

\section{RESUMEN}

Las cianobacterias comprenden un grupo de microorganismos del dominio Bacteria (Woese et al. 1990) poco estudiado en Costa Rica. Los escasos trabajos realizados abordan temáticas relacionadas con la ocurrencia de cianobacterias en plantas de tratamiento y la evaluación de su potencial como indicadoras de contaminación o la producción de toxinas. En la presente investigación se analizó la diversidad y distribución de cianobacterias bentónicas marinas en diferentes puntos del Caribe central y sur de Costa Rica. Los resultados obtenidos muestran una ocurrencia de 17 géneros taxonómicos, 4 de ellos pertenecen a Chroococcales (24\%), 2 Nostocales (12\%) y 11 Oscillatoriales (64\%). Las poblaciones de cianobacterias se mantienen relativamente constantes a lo largo de los meses de escasa precipitación cuando las aguas se mantienen calmas y claras, mientras que en la estación lluviosa o cuando se presenta gran cantidad de sedimentos suspendidos y fuertes oleajes las poblaciones disminuyen en forma notable. Los géneros Lyngbya, Phormidium, Oscillatoria, Spirulina y Leptolyngbya se encuentran distribuidos en prácticamente todas las zonas muestreadas, sin embargo, el género Lyngbya alcanza poblaciones muy importantes en los puntos de muestreo del Caribe central, en especial en Isla Uvita, donde es posible localizar un gran número de colonias de Lyngbya majuscula y Lyngbya confervoides, especies que están relacionadas con ambientes alterados por el ser humano.

Palabras claves: Cianobacteria, bentos, diversidad.

\begin{abstract}
Cyanobacteria constitute a group of microorganisms belonging to the Bacteria domain (Woese et al. 1990). Little has been studied about it in Costa Rica and those studies have addressed issues related to the occurrence of cyanobacteria in water treatment plants and the assessment of their potential as toxin production or pollution indicators. In the present paper the occurrence of benthic marine algae is examined in different parts of the central and southern Caribbean of Costa Rica. The results show an occurrence of 17 genera distributed among 4 Chroococcales (24\%), 2 Nostocales (12\%), and 11 Oscillatoriales (64\%). Cyanobacteria populations remain relatively constant throughout the months of limited rainfall when the waters remain calm and clear, while in the rainy season or when there is a large amount of suspended sediments and heavy swells populations decline significantly. The genera Lyngbya, Phormidium, Oscillatoria, Spirulina and Leptolyngbya are distributed in virtually all areas sampled; however the genus Lyngbya reaches important populations in the sampling points of the central Caribbean, especially near Uvita Island where they can be found in large numbers of colonies Lyngbya majuscula and Lyngbya confervoides, species that are related to environments altered by human activity.
\end{abstract}

Keywords: Cyanobacteria, benthos, diversity.

1 Laboratorio de biotecnología de microalgas, Universidad Nacional, Heredia, Costa Rica, Apdo. 86-3000. Telefax (506)22773089.nmunoz@una.ac.cr*

Recibido 13-IX-2010

Aceptado 31-VII-2012

DOI: http://dx.doi.org/10.15359/revmar.4.1 


\section{INTRODUCCIÓN}

Las cianobacterias, conocidas tradicionalmente como algas azul-verdes, comprenden un grupo de microorganismos procariotas autótrofos fotosintéticos que poseen la capacidad de sintetizar clorofila a (Whitton \& Potts, 2000), y el pigmento ficobilínico ficocianina (Cronberg \& Annadotter, 2006), que les concede el color azulado; en ciertas condiciones algunos organismos pueden sintetizar el pigmento ficoeritrina que le otorga al alga una coloración rojiza o púrpura (Lee, 1999).

Son un grupo ancestral, cuyo origen se calcula que ocurrió hace 3500 millones de años atrás en el período precámbrico. Pueden colonizar una gran diversidad de hábitats, suelo, rocas, plantas, agua dulce, agua salobre y agua marina (Wehr \& Sheath, 2002). En este grupo se encuentran especies que pueden colonizar además ambientes extremos como los ecosistemas hipersalinos, las fuentes termales o la nieve, posee también representantes de distribución cosmopolita con una elevada plasticidad adaptativa (Whitton \& Potts, 2000); algunas especies pueden formar asociaciones con plantas y animales, mientras que otras tienen la capacidad de fijar nitrógeno molecular, lo que ayuda a la fertilización del suelo y al enriquecimiento de la columna de agua en el caso de las especies marinas. En esta clase se pueden encontrar especies de un gran potencial económico que producen metabolitos secundarios de un gran valor económico utilizados como agentes terapéuticos (Linington et al. 2009; Tripathi et al. 2010) de control biológico (Soltani et al. 2005; Mian et al. 2003) y como base para la síntesis de moléculas más complejas (Conroy et al. 2010; Bandyopadhyay et al. 2011) y pigmentos accesorios que son de alto valor agregado.
La morfología más simple en el grupo es la cocoide. En ella las células pueden encontrarse libres o rodeadas de una envoltura mucilaginosa (Lee, 1999). En algunas especies, la fisión binaria es incompleta y cada célula hija puede permanecer comunicada con sus vecinas mediante plasmodesmos, el conjunto puede organizarse en una hilera denominada tricoma, que en ocasiones puede rodearse de una vaina mucilaginosa para denominarse filamento. Este puede ser uniseriado si posee un solo tricoma, o multiseriado si posee varios (Lee, 1999; Whitton \& Potts, 2000; Boone et al. 2001). El talo más complejo en las cianobacterias es un filamento ramificado, que puede poseer una o varias filas de células. Todas las características mencionadas anteriormente son de importancia para determinar los órdenes en que se clasifica a la clase cyanophyceae (Desikachary, 1959; Lee, 1999; Boone et al. 2001).

La distribución y taxonomía de las cianobacterias marinas en Costa Rica ha sido poco estudiada; algunos trabajos se enfocan en las especies potencialmente tóxicas en plantas de tratamiento de agua para consumo humano (Peinador, 1992), especies bioindicadoras de contaminación orgánica en aguas para consumo (Peinador, 1999), aislamiento e identificación de especies provenientes de aguas termales (Rojas, 2004) y cianobacterias de suelos y agua dulce (González, 1970). El estudio de las cianobacterias marinas bentónicas sigue siendo un enigma en nuestro país; los escasos trabajos realizados se enfocan únicamente en las especies planctónicas involucradas en floraciones algales nocivas (Vargas-Montero \& Freer, 2004) que constituyen un porcentaje muy bajo de toda la diversidad que puede presentarse en nuestras costas.

El presente trabajo constituye el primer esfuerzo dirigido a conocer la 
diversidad de cianobacterias bentónicas marinas en diferentes puntos de la costa del Caribe de Costa Rica.

\section{MATERIALES Y MÉTODOS}

El muestreo se llevó a cabo entre enero y noviembre del 2008, y se organizó de tal manera que se incluyeran los meses con estación lluviosa (noviembre, enero, febrero, mayo, junio y julio) y los meses de menor precipitación (abril, setiembre y octubre). Se establecieron 5 estaciones de muestreo que fueron georreferenciados con un GPS Magellan Explorist 210 (Cuadro 1).

En cada estación se hicieron observaciones sobre las condiciones del tiempo, oleaje y visibilidad en la columna de agua, y seguidamente se estableció un mínimo de tres transectos lineales perpendiculares a la costa, a lo largo de los cuales se tomaron de forma manual las muestras, el material recolectado se depositó en bolsas plásticas, a la vez que se anotaron las características del sustrato (arenoso, coral muerto, rocas, pastos marinos o macroalgas), así como los caracteres propios de los talos (forma y coloración). Las muestras se transportaron vivas en sus respectivas bolsas plásticas hasta el Laboratorio de Biotecnología de Microalgas en la
Universidad Nacional, donde se reconocieron preliminarmente con la ayuda de un microscopio fotónico marca Optima XS$6300 \mathrm{~V}$ bajo un aumento de 200x y 400x. Luego, el material se separó en dos partes; la primera porción se mantuvo viva para ser agregada en $125 \mathrm{ml}$ de medio de cultivo Provasoli o ASN-III, estas muestras se mantuvieron a $21^{\circ} \mathrm{C}$ bajo una irradiancia de $20 \mu \mathrm{mol} . \mathrm{m}^{-2} \cdot \mathrm{s}^{-1} \mathrm{y}$ un fotoperíodo de 12 $\mathrm{h}$ día y $12 \mathrm{~h}$ oscuridad. La segunda porción se subdividió en dos, una se fijó con solución de lugol y otra con formaldehído, posteriormente, el material se identificó a 400x y 1000x, con ayuda de un microscopio de luz marca motic BA210 equipado con una cámara fotográfica motic A640.

La clasificación taxonómica de las especies de cianobacterias marinas se llevó a cabo adoptando el sistema propuesto por Komárek y Anagnostidis (1989; 1999; 2005).

Las cianobacterias fijadas fueron depositadas en la colección de cultivos de microalgas de la Escuela de Ciencias Biológicas de la Universidad Nacional, mientras que el material vivo se utilizó principalmente para la obtención de nuevas cepas para la valoración de especies con potencial biotecnológico.

Cuadro 1. Estaciones de muestreo de cianobacterias marinas bentónicas en el Caribe costarricense y sus respectivas coordenadas

Table 1. Sampling stations of benthic marine cyanobacteria along the Costa Rican Caribbean coast and their respective coordinates

\begin{tabular}{l|c}
\hline Estación de muestreo & Coordenadas \\
\hline Manzanillo & $9^{\circ} 38^{\prime} 20.8^{\prime \prime} \mathrm{N}-82^{\circ} 45^{\prime} 12.5^{\prime \prime} \mathrm{O}$ \\
Puerto Viejo & $9^{\circ} 39^{\prime} 28.16^{\prime \prime} \mathrm{N}-82^{\circ} 45^{\prime} 12.53^{\prime \prime} \mathrm{O}$ \\
Puerto Vargas & $9^{\circ} 44^{\prime} 18.69^{\prime}{ }^{\prime} \mathrm{N}-82^{\circ} 48^{\prime} 39.98^{\prime}, \mathrm{O}$ \\
Isla Uvita & $9^{\circ} 59^{\prime} 35.87^{\prime \prime} \mathrm{N}-83^{\circ} 00^{\prime} 44.2^{\prime \prime} \mathrm{O}$ \\
Piuta & $10^{\circ} 00^{\prime} 10.566^{\prime} \mathrm{N}-83^{\circ} 01^{\prime} 54.41^{\prime}, \mathrm{O}$ \\
\hline
\end{tabular}




\section{RESULTADOS}

En las muestras fijas se identificó un total de 17 géneros taxonómicos distribuidos en 3 órdenes: Chroococcales (24\%), Nostocales (12\%) y Oscillatoriales (64\%). Los géneros más comunes fueron: Lyngbya, Phormidium, Oscillatoria, Spirulina y
Leptolyngbya, encontrándose en prácticamente todas las estaciones de muestreo a lo largo del año (Cuadros 2 y 3 ).

Se identificó un total de 21 taxones (Cuadros 2 y 3 ) y con base en las observaciones realizadas se propuso una clave taxonómica para la identificación de las especies presentes en la costa del Caribe.

Cuadro 2. Géneros y especies de cianobacterias encontradas en las estaciones de muestreo durante los meses de estación seca

Table 2. Genera and species of cyanobacteria by sampling station during dry season

\begin{tabular}{lccccc}
\hline \multicolumn{1}{c}{ Género o especie } & Manzanillo & Puerto Viejo & Puerto Vargas & Isla Uvita & Piuta \\
\hline Chamaecalyx leibleiniae & - & - & - & - & + \\
Geitlerinema cf exile & - & + & - & - & + \\
Leibleinia cf gracilis & - & - & - & - & + \\
Johannesbaptistia pellucida & - & - & + & - & - \\
Lyngbya aestuarii & - & - & + & + & - \\
Lyngbya confervoides & + & + & - & + & + \\
Lyngbya majuscula & + & - & + & + & + \\
Lyngbya semiplena & + & - & - & - & - \\
Coleofasciculus chtononoplastes & - & - & - & - & + \\
Nodularia harveyana & - & - & $+*$ & + & - \\
Osillatoria bonnemaisonii & - & + & - & - & - \\
Oscillatoria curviceps & - & + & - & + & - \\
Oscillatoria limosa & + & - & + & - & - \\
Oscillatoria nigro-viridis & - & - & - & - & + \\
Oscillatoria terebriformis & + & - & - & + & + \\
Phormidium corium & - & + & + & - & + \\
Phormidium fragile & - & - & - & + & - \\
Phormidium laysanense & + & - & - & - & - \\
Stichosiphon cf sansibaricus & - & - & + & + & - \\
Symploca cf furnicularis & - & + & - & - & - \\
Symploca hydnoides & + & + & + & + & + \\
Borzia sp. & - & $+*$ & - & - & + \\
Calothrix sp. & - & - & + & - & - \\
Chroococus sp. & + & - & - & - & - \\
Leptolyngbya sp. & + & + & + & + & + \\
Pseudanabaena sp. & + & + & + & + \\
Spirulina sp. & + & + & + & + \\
\hline La especie & + & + & + & + & + \\
\hline
\end{tabular}

*La especie se identifica en cultivos, no en la muestra de referencia. 
Cuadro 3. Géneros y especies de cianobacterias encontradas en las estaciones de muestreo durante los meses de estación lluviosa

Table 3. Genera and species of cyanobacteria by sampling station during rainy season

\begin{tabular}{|c|c|c|c|c|c|}
\hline Género o especie & Manzanillo & Puerto Viejo & Puerto Vargas & Isla Uvita & Piuta \\
\hline Chamaecalyx leibleiniae & - & - & - & - & - \\
\hline Geitlerinema cf exile & - & + & - & - & + \\
\hline Leibleinia cf gracilis & - & - & - & - & - \\
\hline Johannesbaptistia pellucida & - & - & - & - & - \\
\hline Lyngbya aestuarii & - & - & + & - & - \\
\hline Lyngbya confervoides & + & + & - & + & + \\
\hline Lyngbya majuscula & + & - & + & - & - \\
\hline Lyngbya semiplena & + & - & + & - & - \\
\hline Coleofasciculus chtononoplastes & - & - & - & - & + \\
\hline Nodularia harveyana & - & - & - & - & - \\
\hline Osillatoria bonnemaisonii & - & - & - & - & - \\
\hline Oscillatoria curviceps & - & + & - & - & - \\
\hline Oscillatoria limosa & - & - & + & - & - \\
\hline Oscillatoria nigro-viridis & - & - & - & - & - \\
\hline Oscillatoria terebriformis & - & - & - & - & + \\
\hline Phormidium corium & - & - & + & - & + \\
\hline Phormidium fragile & - & - & - & - & - \\
\hline Phormidium laysanense & + & - & + & - & - \\
\hline Stichosiphon cf sansibaricus & - & - & - & - & - \\
\hline Symploca cf furnicularis & - & - & - & - & - \\
\hline Symploca hydnoides & + & + & + & + & + \\
\hline Borzia sp. & - & - & - & - & - \\
\hline Calothrix sp. & - & - & - & - & - \\
\hline Chroococcus sp. & - & - & - & - & - \\
\hline Leptolyngbya $\mathrm{sp}$. & + & + & + & + & + \\
\hline Pseudanabaena sp. & + & + & $+*$ & - & - \\
\hline Spirulina sp. & - & - & - & $+*$ & - \\
\hline
\end{tabular}

* La especie se identifica en cultivos, no en la muestra de referencia.

\section{Clave para la identificación de géneros y especies de cianobacterias bentónicas ma- rinas presentes en el Caribe de Costa Rica}

1A. Talo unicelular o pseudofilamentoso, las células esféricas u ovaladas pueden estar envueltas en un mucílago de forma individual o colectiva, las células pueden encontrarse solitarias en sustratos tales como rocas, conchas u otras algas.....

1B. Talo conformado por filamentos o células estrechamente conectadas 5.

2A. Célula esférica u ovoide, epifita unida al sustrato por un pedúnculo muy pequeño Chamaecalyx leibleiniae. 
2B. Células no unidas a un sustrato por pedúnculo 3.

3A. Células esféricas o subesféricas, hemiesféricas después de la división en grupos de 2 a 4 individuos Chroococcus sp.

3B. Células esféricas o discoidales, formando pseudofilamentos o filamentos 4.

4A. Células en forma de disco. Forman pseudofilamentos. División celular en un plano transversal en relación con el talo Johannesbaptistia pellucida.

4B. Célula epifita, esférica al inicio, luego se vuelve cilíndrica, el contenido se divide en una serie de endosporas ovoides o cilíndricas Stichosiphon cf sansibaricus.

5A. Tricoma con heterocistos 6.

5B. Tricoma sin heterocistos 7.

6A. Heterocistos basales, más amplios que el resto de las células, tricoma se atenúa hacia el ápice, donde las células se vuelven extremadamente delgadas

Calothrix sp.

6B. Heterocistos intercalares, comprimidos hacia el centro, raramente terminales, tricomas y filamentos isopolares Nodularia harveyana.

7A. Talos con vaina mucilaginosa siempre presente. 13.

7B. Talos sin vaina mucilaginosa o presente muy excepcionalmente 8.

8A. Talo espiralado de manera regular, cada vuelta puede ser abierta o cerrada, talos con alta movilidad, movimiento de desplazamiento de tipo rotatorio

Spirulina sp.

8B. Tricomas rectos o levemente retorcidos 9.

9A. Tricomas constreñidos, células de cuadradas a cilíndricas. 10.

9B. Tricomas no constreñidos o rara vez, células de cuadradas a cilíndricas. 12.

10A. Tricomas solitarios o en grupos pequeños, células más cortas que anchas, tricomas altamente constreñidos en las paredes transversales, células apicales no varían en forma con respecto a las del resto del tricoma.

Borzia sp. 
10B. Tricomas solitarios o en grupos, células cilíndricas más largas que anchas, tricomas constreñidos en las paredes transversales

11A. Tricomas cilíndricos, células más largas que anchas, paredes transversales muy constreñidas, células terminales redondeadas, epifitas. Leibleinia cf gracilis.

11B. Tricomas cilíndricos, células más largas que anchas, paredes transversales muy constreñidas, célula apical cónica. Puede encontrarse formando tapetes finos sobre el sustrato. Adaptación cromática presente

Pseudanabaena sp.

12A. Tricomas con gran movimiento de deslizamiento acompañado de rotación del tricoma, células más largas que anchas, las constricciones en las paredes transversales son muy raras, y si ocurren son muy superficiales, tricomas gradualmente atenuados, célula apical en forma de gancho

Geitlerinema cf exile.

12B. Tricomas con movimiento de deslizamiento, células más cortas que anchas sin constricciones en las paredes transversales Oscillatoria.

$12 \mathrm{~B}_{1}$. Tricomas rectos, célula apical redondeada con un engrosamiento ligero.. O. limosa.

$12 \mathrm{~B}_{2}$. Tricomas rectos, curvados en el extremo apical O. curviceps.

$12 \mathrm{~B}_{3}$. Tricomas atenuados y doblados hacia los extremos, células $1.2-1.6 \mu \mathrm{m} \mathrm{x}$ 5.4-6.0 $\mu \mathrm{m}$. O. nigro-viridis.

$12 \mathrm{~B}_{4}$. Tricomas serpenteantes y atenuados hacia los extremos, célula terminal no capitada y sin caliptra, células 3.1-8.0 $\mu \mathrm{m} \times 3.1-8.3 \mu \mathrm{m}$.

O. cf terebriformis.

$12 \mathrm{~B}_{5}$. Tricomas levemente curvados, coloración de roja a violeta.

O. bonnemaisonii.

13A. Filamentos con varios tricomas por vaina, los tricomas pueden escapar fácilmente de la vaina y presentan células más largas que anchas.....

Coleofasciculus chtonoplastes.

13B. Filamentos con un solo tricoma por vaina. 14.

14A. Filamentos menores a $3 \mu \mathrm{m}$ de ancho, células más largas que anchas o isodiamétricas, vaina persistente pero no firme Leptolyngbya sp. 
14B. Filamentos mayores a $3 \mu \mathrm{m}$ de diámetro 15.

15A. Filamentos sin ramificación falsa 16.

15B. Filamentos con ramificación falsa frecuente Symploca.

$15 \mathrm{~B}_{1}$. Células apicales capitadas y con una pequeña caliptra Symploca cf furnicularis.

$15 \mathrm{~B}_{2}$. Células apicales no capitadas y sin caliptra Symploca hydnoides.

16A. Vaina mucilaginosa extremadamente delgada muy adherida al tricoma, difícil de observar con el microscopio de luz, tricoma cilíndrico con células usualmente cuadradas Phormidium.

16A $\mathrm{A}_{1}$. Filamentos muy largos con células isodiamétricas, célula apical redondeada, dimensiones: 4.5-5 $\mu \mathrm{m}$ x 2.9-6.0 $\mu \mathrm{m}$ P. corium.

$16 \mathrm{~A}_{2}$. Filamentos con células más largas que anchas, atenuados, célula apical cónica, dimensiones: 1.9-2.6 $\mu \mathrm{m} \times 2.2-2.5 \mu \mathrm{m}$ P. fragile.

16A $\mathrm{A}_{3}$ Filamentos cortos, células más largas que anchas, célula apical plana o cónica-plana, dimensiones: 4.3-4.9 $\mu \mathrm{m} \times$ 4.6-4.9 $\mu \mathrm{m}$.

P. laysanense.

16B. Vaina firme que se extiende más allá de la célula terminal del tricoma, células más anchas que largas, con forma de disco Lyngbya.

$16 \mathrm{~B}_{1}$. Vaina fina, hialina, célula apical convexa L. confervoides.

$16 \mathrm{~B}_{2}$. Vaina extremadamente gruesa, hasta $9 \mu \mathrm{m}$, lamelada, células muy anchas en forma de disco, tricomas con varias tonalidades de rojo a violeta........

L. majuscula.

$16 \mathrm{~B}_{3}$. Vaina gruesa hasta $3 \mu \mathrm{m}$, lamelada, célula terminal capitada o con caliptra L. semiplena.

$16 \mathrm{~B}_{4}$. Vaina gruesa en filamentos viejos, lamelada, células apicales planas

L. aestuarii. 


\section{Descripción de algunos géneros y especies de cianobacterias bentónicas marinas presentes en el Caribe costarricense}

\section{Orden Chroococcales}

Familia Chamaesiphonaceae

Chamaecalyx leibleiniae (Reinsch)

Komárek \& Anagnostidis 1986. (Figs. 1 y 2)

Esporangios ovalados, alargados o piriformes de $4 \mu \mathrm{m}$ de diámetro. Coloración verde claro. Células fijas al sustrato por medio de un pequeño pedúnculo. La primera división celular es transversal con respecto a la célula madre.

Hábitat: epifita sobre Lyngbya sp.

\section{Familia Entophysalidaceae}

Johannesbaptistia pellucida (Dickie)

W. R. Taylor \& Drouet 1938: 285

Filamento levemente curvado con células en forma de disco o morfologías intermedias entre esferas y discos.

Nota: solo se logra encontrar un filamento mezclado entre varios filamentos de Lyngbya.

\section{Familia Chroococcaceae}

\section{Chroococcus sp.}

Células semiesféricas con contenido celular homogéneo, de color verde azulado. Vaina hialina.

Nota: solo se encuentran dos organismos entre varios filamentos de Lyngbya $\mathrm{sp}$, por lo que no se logra obtener suficiente información.

\section{Stichosiphon cf sansibaricus}

(Hieronymus) Drouet \& Daily 1956. (Fig. 3)

Filamentos de 5-6 $\mu \mathrm{m}$ de diámetro. Célula basal esférica, contenido celular homogéneo de color verde azulado. Vaina hialina delgada. Dimensiones celulares: no se encuentra suficiente material.

Hábitat: epifita.
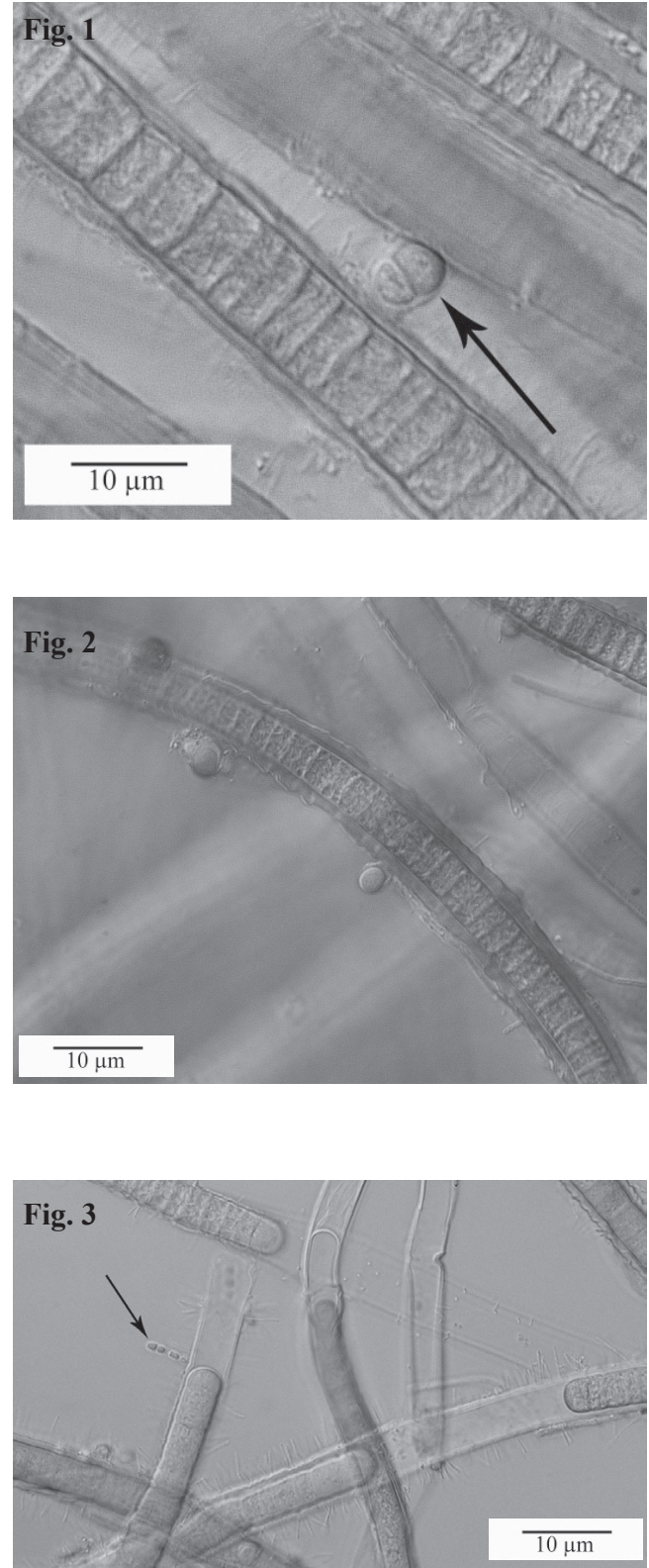

Figs. 1-3. 1 y 2. Chamaecalyx leibleiniae. Célula sobre vaina mucilaginosa de Lyngb$y a$ sp. 2. Detalle de la primera división celular. 3. Stichosiphon of sansibaricus apariencia general

Figs. 1-3. 1 \& 2. Chamaecalyx leibleiniae. Cell growing over a sheath of Lyngbya sp. 2. Details of the first cell division. 3. Stichosiphon cf sansibaricus. General appearance 


\section{Orden Oscillatoriales}

Familia Oscillatoriaceae

\section{Lyngbya aestuarii}

Liebman ex Gomont, Ann. Sci. Nat. Bot. 16: 127. 1892. (Fig. 4)

Filamentos largos con una vaina lamelada firme. Células más anchas que largas y en forma de disco. Célula apical puede tener varias formas: cónica, truncada o capitada o plana con una membrana engrosada. Dimensiones celulares: 10-16 $\mu \mathrm{m}$ x 2.7-5.6 $\mu \mathrm{m}$.

Hábitat: puede encontrarse sobre arena, corales, macroalgas y pastos marinos.

\section{Lyngbya confervoides}

C. Agardh ex Gomont, Ann. Sci. Nat. Bot. 16: 136. 1892. (Figs. 5 y 6)

Filamentos enmarañados, de coloración verde-café, vainas hialinas incoloras, muy firmes y delgadas, en ocasiones estratificadas. Células cortas en forma de disco. Dimensiones celulares: $10.5 \mu \mathrm{m}$ (10-16) x $3 \mu \mathrm{m}(2-4)$.

Hábitat: las colonias pueden crecer sobre arena, rocas, corales, troncos o cualquier superficie en que puedan fijarse.

\section{Lyngbya majuscula}

Harvey ex Gomont 1892. Ann. Sci. Nat. Bot., ser. 7, 16: 131. (Figs. 7-9)

Colonias voluminosas de color rojo, de varios centímetros de longitud. Filamentos muy largos, curvados o rectos, no constreñidos. Vaina muy gruesa $(9 \mu \mathrm{m})$ y lamelada, incolora. Tricomas de color rojo a rosado. Células extremadamente anchas y muy bajas, de forma discoidal. Dimensiones: 32.9 $\mu \mathrm{m}$ (30.4-34.2) x $11.3 \mu \mathrm{m}$ (8.0-14.4).

Hábitat: se encuentra en todo tipo de sustrato: rocas, coral, cuerdas, esponjas y Sargassum sp.

\section{Lyngbya semiplena}

J. Agardh ex Gomont, Ann. Sci. Nat. Bot. 16: 138. 1892. (Figs. 10 y 11)

Filamentos solitarios, largos, rectos, flexibles. Tricomas atenuados hacia el ápice. Células más anchas que largas. Dimensiones celulares: $12.4 \mu \mathrm{m}$ (9.7-14) x $4.5 \mu \mathrm{m}$ (2.7-6.0). Células terminales frecuentemente poseen una terminación en forma de domo transparente.

Hábitat: se encuentra sobre rocas y otras algas.
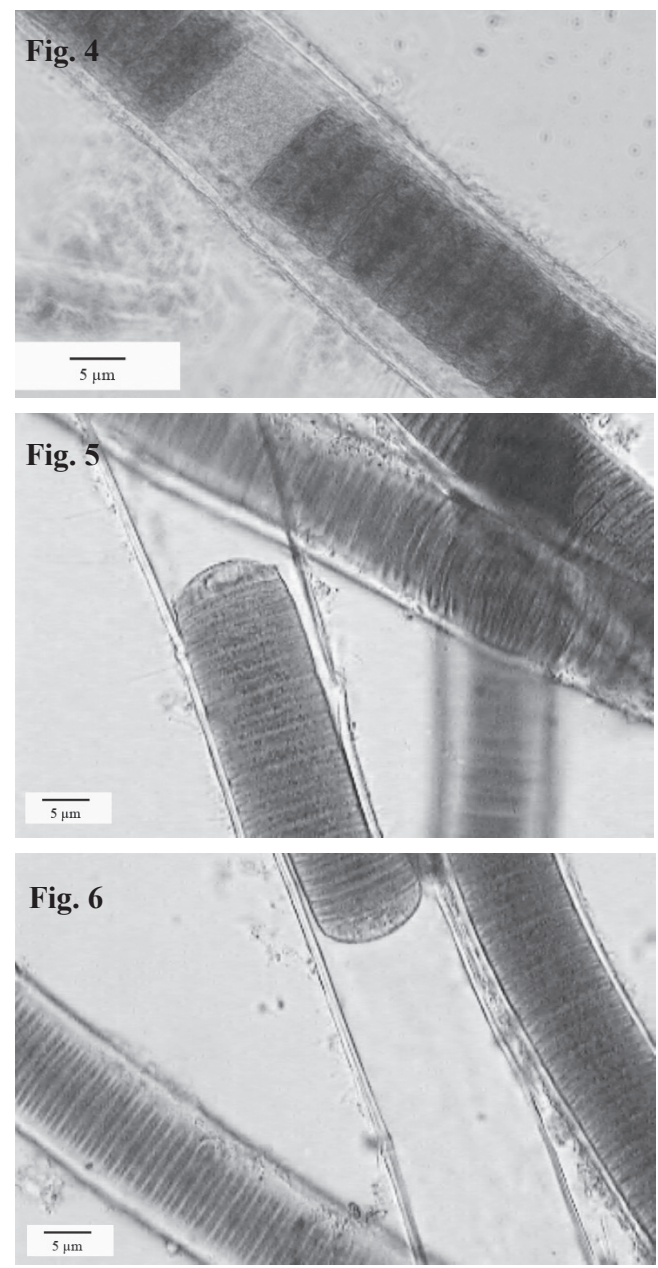

Figs. 4-6. 4. Lyngbya aestuarii. 5 y 6. Lyngbya confervoides. Detalle de los filamentos

Figs. 4-6. 4. Lyngbya aestuarii. 5 \& 6. Lyngbya confervoides. Details of filaments 


\section{Oscillatoria curviceps}

Agardh ex Gomont 1892. Ann. Sci. Nat. Bot., ser. 7, 16: 213. (Figs. 12 y 13)

Filamentos rectos, torcidos hacia el extremo y no constreñidos en las paredes transversales. Células terminales redondeadas. Células miden 10-17 $\mu \mathrm{m} \times 2-5$ $\mu \mathrm{m}$. Las colonias forman tapetes con coloración café-crema.

Hábitat: se encuentra sobre fondos areno-limosos que se localizan comúnmente en zonas muy protegidas de la turbulencia.
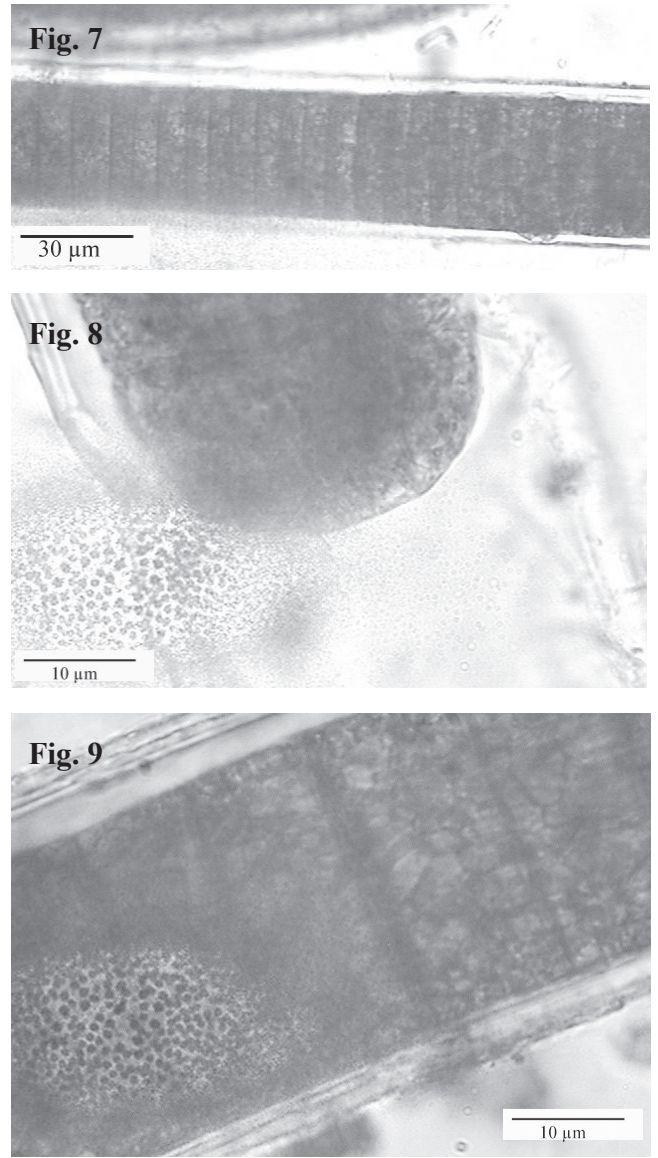

Figs. 7-9. 7, 8 y 9. Lyngbya majuscula. 7. Detalle del filamento. 8. Detalle de la célula apical. 9. Detalle del tricoma

Figs. 7-9. 7, 8 \& 9. Lyngbya majuscula. 7 Details of the filament. 8. Details of the apical cell. 9. Details of the trichome
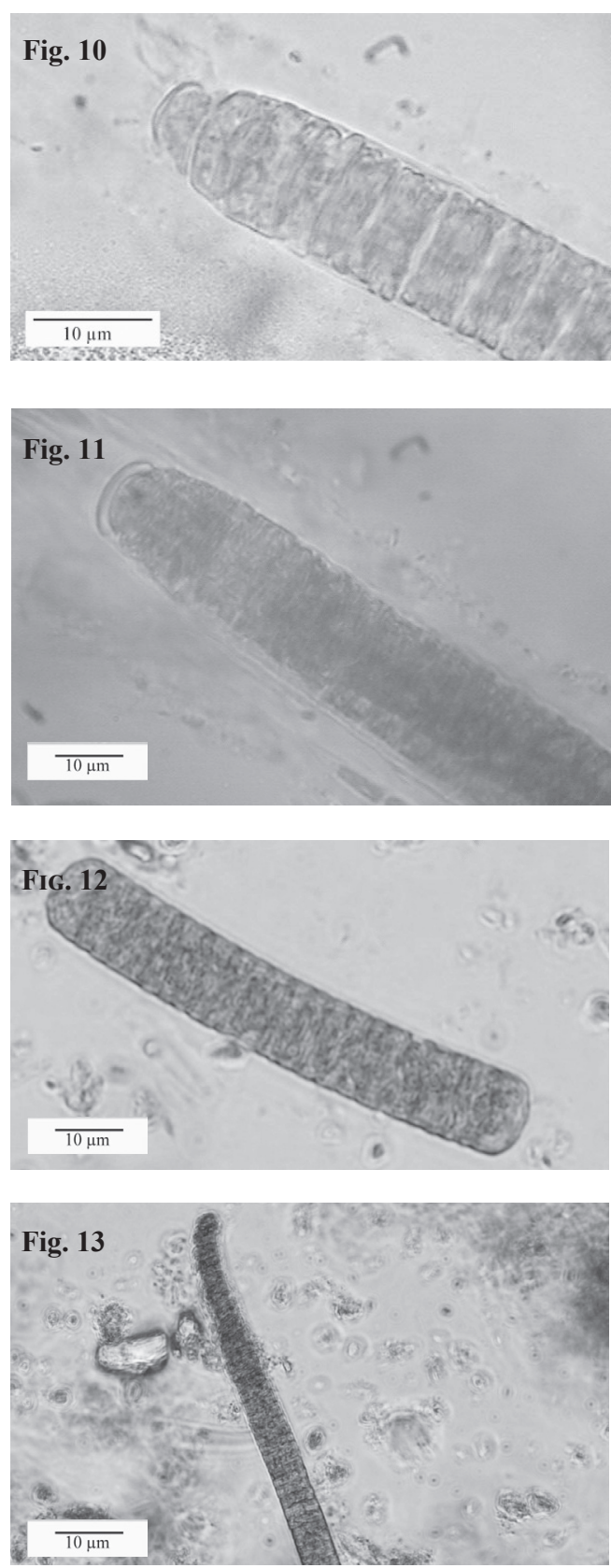

Figs. 10-13. 10 y 11. Lyngbya semiplena. Apariencia general del tricoma y el filamento. 12 y 13. Oscillatoria curviceps. 12. Morfología general. 13. Detalle del hormogonio

Figs. 10-13. 10 \& 11. Lyngbya semiplena. General appearance of the trichome and filamen. 12 \& 13. Oscillatoria curviceps. 12. General morphology. 13. Details of the hormogonium 


\section{Oscillatoria limosa}

Agardh ex Gomont 1892. Ann. Sci. Nat. Bot., ser. 7, 16: 210. (Fig. 14)

Tricomas rectos, no atenuados hacia los extremos. Célula terminal redondeada con un ligero engrosamiento en la membrana, células vegetativas miden 11-20 $\mu \mathrm{m}$ de ancho x 2-5 $\mu \mathrm{m}$ de alto.

Hábitat: se encuentra sobre fondos de arena fina.

\section{Oscillatoria nigro-viridis}

Thwaites ex Gomont, Ann. Sci. Nat. Bot. 16: 217. 1892. (Figs. 15 y 16)

Tricomas de color verde claro, cortos, doblados hacia los extremos y atenuados. Células más cortas que anchas, miden 5.9 $\mu \mathrm{m}$ (5.4-6.0) x $1.4 \mu \mathrm{m}$ (1.2-1.6).

Hábitat: se encuentra sobre fondos de arena fina y fango, en zonas someras.
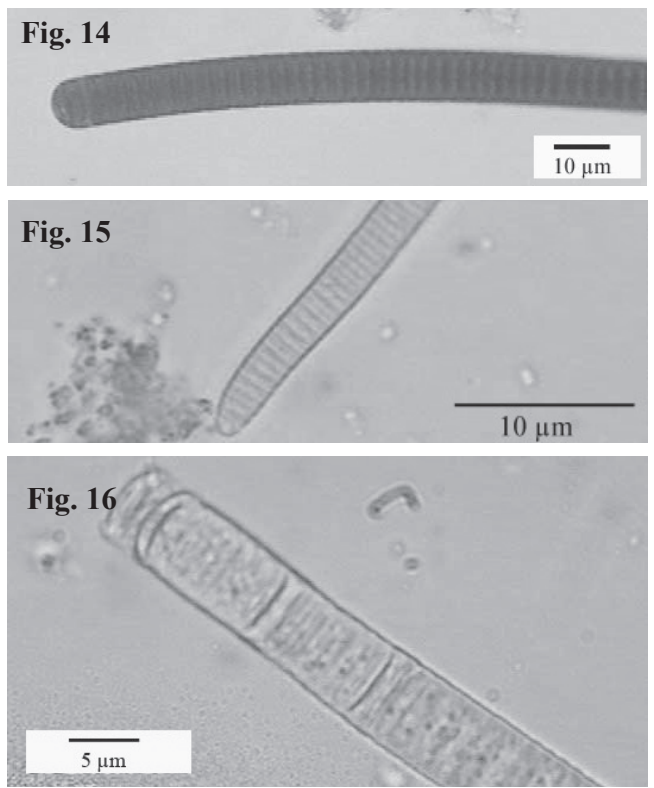

Figs. 14-16. 14. Oscillatoria limosa. Apariencia general. 15 y 16 . Oscillatoria nigro-viridis. 15 . Detalle del tricoma. 16. Detalle de los necridios

Figs. 14-16. 14. Oscillatoria limosa. General appearance. 15 \& 16. Oscillatoria nigro-viridis 15 . Details of the trichome. 16. Details of necridia

\section{Oscillatoria cf terebriformis}

Agardh ex Gomont 1892. Ann. Sci. Nat. Bot., ser. 7, 16: 234. (Figs. 17 y 18)

Tapete verde brillante. Tricoma de coloración verde, atenuado hacia los extremos y levemente torcido. Contenido celular granuloso. Célula terminal levemente redondeada, no capitada y sin caliptra. Dimensiones celulares $6.3 \mu \mathrm{m}(3.1-8.0) \times 5.5 \mu \mathrm{m}(3.1-8.3)$.

Hábitat: se encuentra en zona arenosa.

\section{Oscillatoria bonnemaisonii}

Crouan ex Gomont 1892. Ann. Sci. Nat. Bot., ser. 7, 16: 215. (Fig. 19)

Tricoma de color violeta o rojo, sin caliptra. Filamentos muy largos que se encuentran creciendo sobre un alga roja no identificada. Dimensiones celulares: 18-30 $\mu \mathrm{m}$ x 4-6 $\mu \mathrm{m}$.
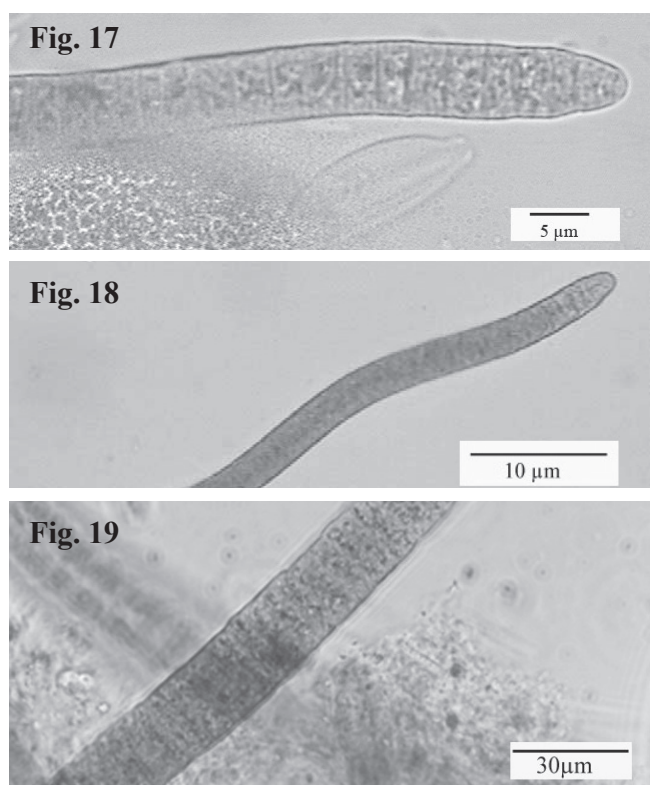

Figs. 17-19. 17 y 18. Oscillatoria cf terebriformis. 17. Detalle del tricoma y célula apical. 18. Aspecto del tricoma. 19. Oscillatoria bonnemaisonni. Apariencia del tricoma

Figs. 17-19. 17-18. Oscillatoria cf terebriformis.17. Details of the trichome and apical cell. 18. Trichome aspect. 19. Oscillatoria bonnemaisonni. Appearance of the trichome. 


\section{Familia Borziaceae}

Borzia sp. (Fig. 20)

Tricomas solitarios cortos e inmóviles muy constreñidos. Células más largas que anchas.

Nota: solo se puede observar en el cultivo de un filtrado de agua de mar de Puerto Viejo. Crece formando colonias cóncavas aisladas de coloración verde oliva.

\section{Familia Pseudanabaenaceae}

Geitlerinema cf exile

(Skuja) Anagnostidis 1989. (Figs. 21 y 22)

Tapete café oscuro muy compacto. Tricomas con movilidad muy activa. Tricomas rectos y constreñidos de coloración verde pálido. Células más largas que anchas. Contenido celular con gránulos grandes. Células terminales atenuadas, levemente torcidas. Dimensiones celulares: $3.8 \mu \mathrm{m}(3.0-4.7)$ x $4.5 \mu \mathrm{m}$ (3.7-5.0).

Hábitat: crece sobre sustrato arenoso en pozas de baja profundidad.

\section{Leibleinia cf gracilis}

(Rabenhorst ex Gomont) K. Anagnostidis \& J. Komárek. (Figs. 23 y 24)

Células de color verde azulado. Dimensiones: 8 a $11 \mu \mathrm{m}$ de ancho, 1.3 a $3 \mu \mathrm{m}$ de largo. Adheridas al sustrato por todo lo

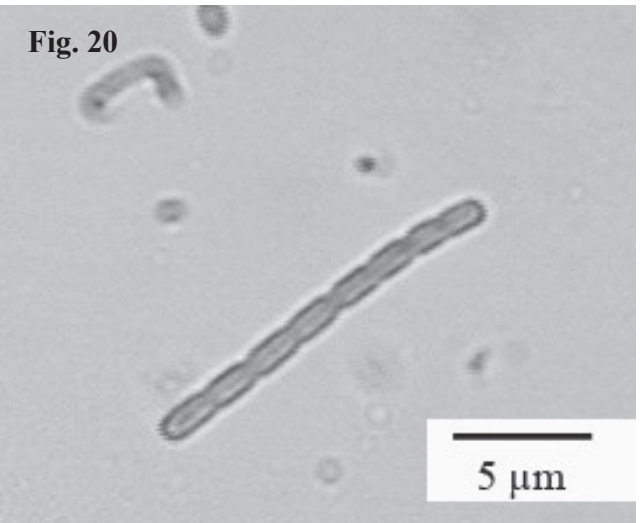

Fig. 20. Borzia sp.

Fig. 20. Borzia sp. largo del filamento. Sin movimiento aparente. Célula apical redondeada.

Hábitat: epifita creciendo sobre Lyngbya sp.
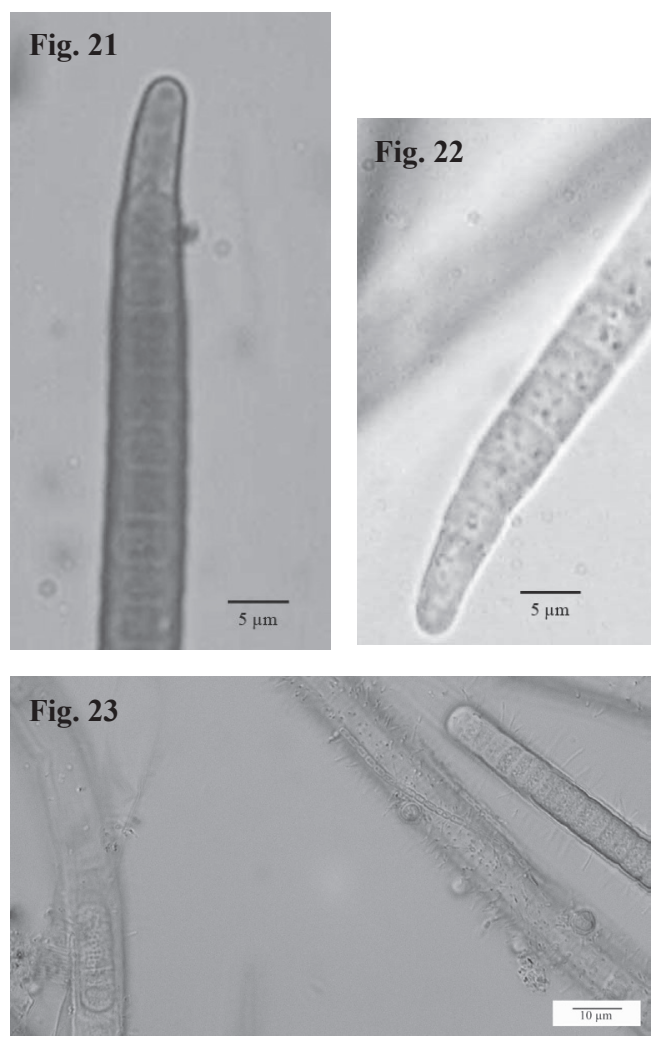

Fig. 24

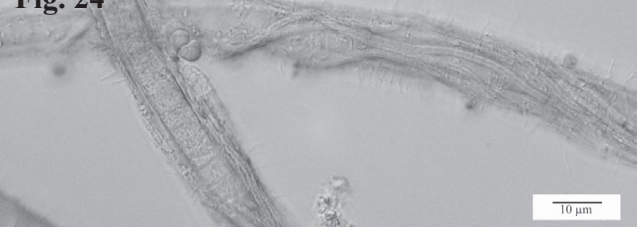

Figs. 21-24. 21 y 22. Geitlerinema cf exile. 21. Detalle del tricoma y la porción apical. 22. Detalle del tricoma. 23 y 24. Leibleinia of gracilis. 23. Filamento sobre la vaina de Lyngbya sp. 24. Detalle varios filamentos serpenteando sobre la vaina de Lyngbya sp.

Figs. 21-24. 21 \& 22. Geitlerinema cf exile. 21. Trichome apical portion. 22. Details of trichome. 23 $\&$ 24. Leibleinia cf gracilis. 23. Filament growing over a Lyngbya sp. 24. Detail on the various filaments winding over the sheath of Lyngbya sp. 
Leptolyngbya sp. (Figs. 25 y 26)

Filamentos extremadamente largos con células $1 / 4$ más largas que anchas 1.7 $\mu \mathrm{m}(1.0-2.3) \times 4.2 \mu \mathrm{m}(3.0-6.8)$.

Hábitat: se encuentra sobre fondos de arena fina en conjunto con $P$. corium y $O$. limosa y en medios enriquecidos.

\section{Familia Phormidiaceae}

Coleofasciculus chtonoplastes

Siegesmund, J. R. Johansen \& Friedl. (Figs. 27 y 28$)$
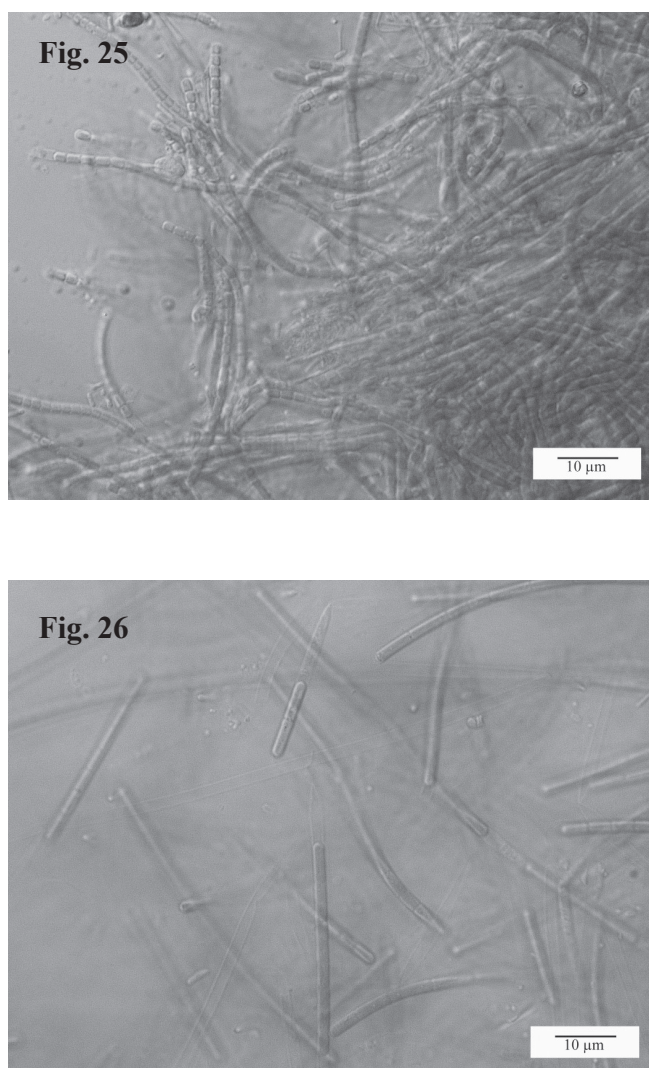

Colonias de color verde oliváceo que crecen como tapetes muy apretados. Filamentos solitarios o entrecruzados, con 8-10 tricomas por vaina. Es frecuente encontrar tricomas solitarios que han escapado de sus respectivas vainas, células cilíndricas más largas que anchas. Dimensiones celulares: $3.1 \mu \mathrm{m}(2.5-3.4) \times 5.1 \mu \mathrm{m}$ (4.1-7.5). Hábitat: se encuentra sobre arena.
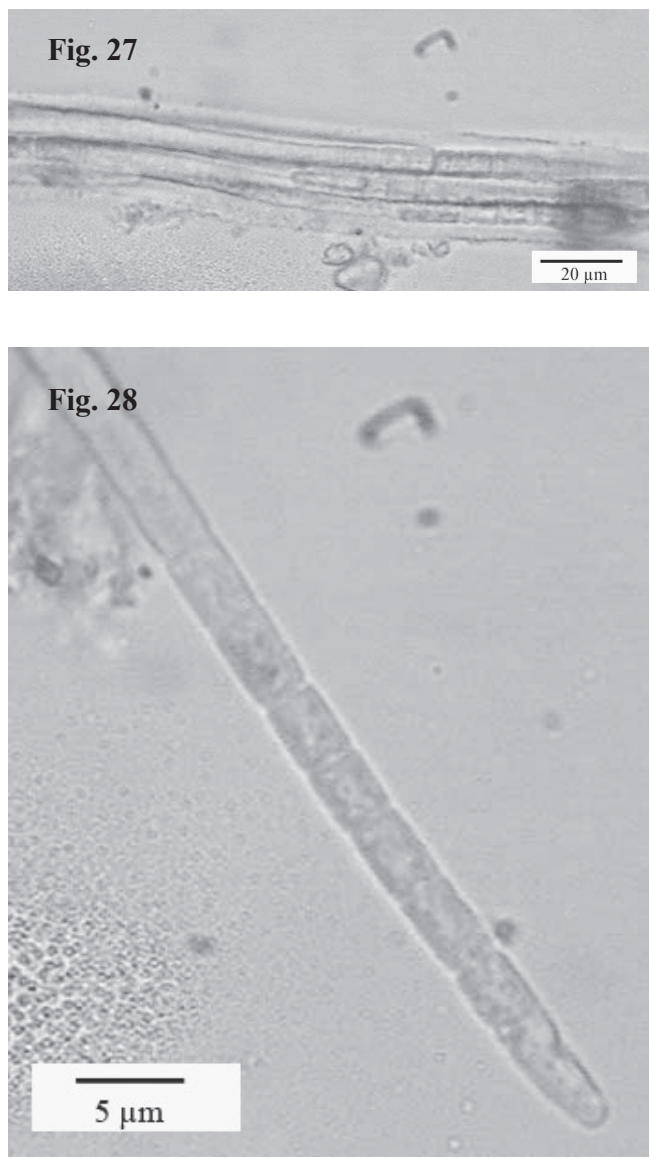

Figs. 25-28. 25 y 26. Leptolyngbya sp. 25. Aspecto general de la colonia. 26. Detalle de los filamentos. 27 y 28. Coleofasciculus chtonoplastes. 27. Detalle del filamento con varios tricomas dentro de una vaina. 28. Detalle del tricoma

Figs. 25-28. $25 \&$ 26. Leptolyngbya sp. 25. General view of the colony. 26. Details of the filaments. $27 \& 28$. Coleofasciculus chtonoplastes. 27. Details of the filament with a number of trichomes within a sheath. 28. Details of trichome 


\section{Phormidium corium}

Kütz. ex Gomont, Ann. Sci. Nat. Bot. 16: 172. 1892. (Figs. 29 y 30)

Filamentos de color verde claro. Tricomas no constreñidos. Vaina hialina muy delgada. Células de apariencia cuadrada a primera vista con dimensiones celulares: $5.1 \mu \mathrm{m}(2.9-6.0)$ x $4.7 \mu \mathrm{m}(4.5-5)$.

Hábitat: se encuentra sobre fondos de arena fina.

\section{Phormidium fragile}

Gomont 1892: 163. (Figs. 31 y 32)

Talo de color verde azulado, muy fino y atenuado a los extremos. Células más largas que anchas o casi cuadradas con un contenido poco granulado. Células apicales en forma cónica muy aguda.
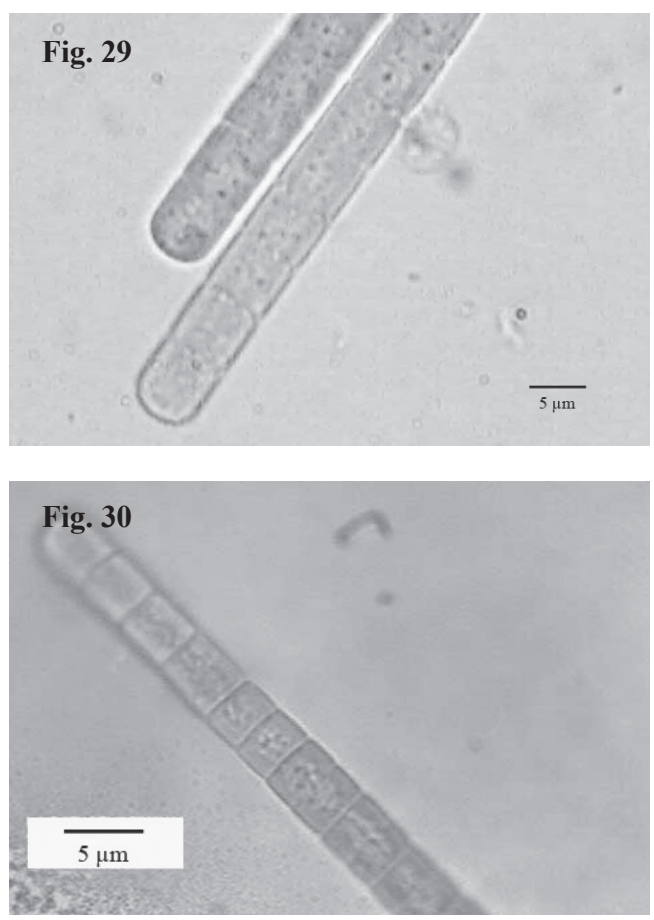

Figs. 29-34. 29 y 30. Phormidium corium. 29. Gránulos en el citoplasma. 30. Aspecto del tricoma. 31 y 32. Phormidium fragile. Detalle del tricoma. 33 y 34. Phormidium laysanense. 33. Apariencia de los tricomas. 34. Detalle de las paredes transversales

Figs. 29-34. 29 \& 30. Phormidium corium. 29. Granules in the cytoplasm 30. Appearance of trichome. 31 \& 32. Phormidium fragile. Details of trichome. 33 \& 34. Phormidium laysanense. 33. Appearance of trichome. 34. Detail of transverse walls 


\section{Symploca cf furnicularis}

Setchell \& Gardner in Gardner 1918.

(Fig. 35)

Colonia de color amarillo-verde de textura gelatinosa. Filamentos de rectos a levemente flexibles. Vaina firme homogénea, visible únicamente en los ápices. No hay pseudorramificación aparente. Células de cuadradas a rectangulares. Células apicales presentan caliptra. Dimensiones celulares: 7 $\mu \mathrm{m}$ (6.9-7.2) x $7.2 \mu \mathrm{m}$ (6.3-7.3).

Hábitat: se encuentra sobre arena en rocas.
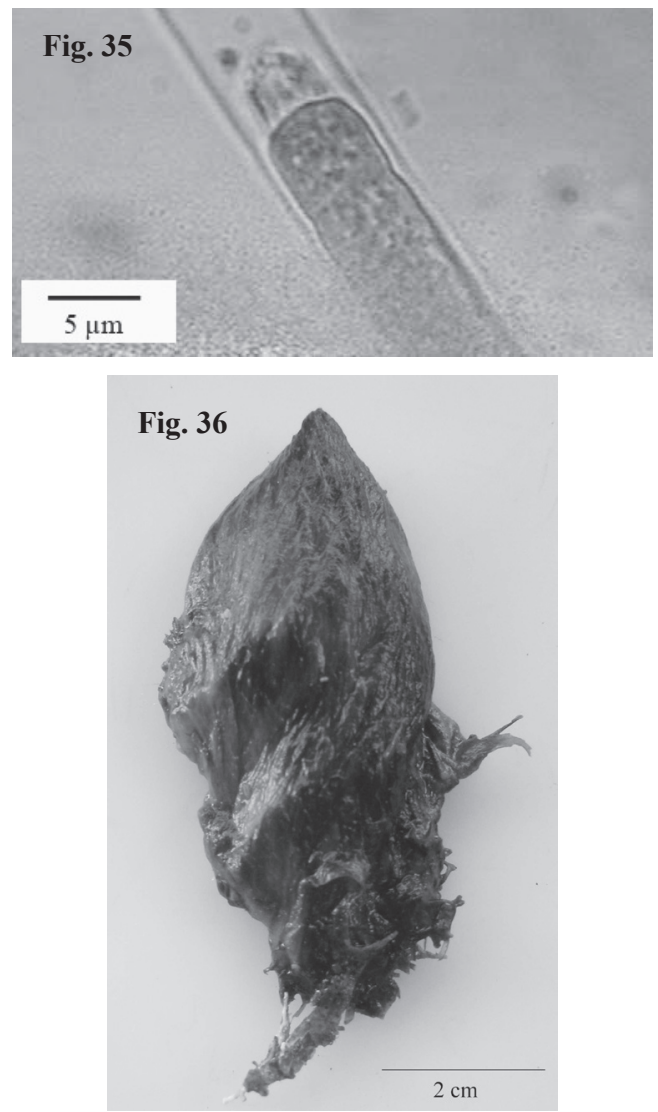

\section{Symploca hydnoides}

Kützing ex Gomont 1892. Ann. Sci. Nat. Bot., ser. 7, 16: 106. (Figs. 36 y 37)

Los talos forman penachos con coloración café y varias tonalidades de verde. Filamentos con vainas hialinas delgadas y firmes, células apicales cónicas redondeadas y sin caliptra. Dimensiones celulares: 5-14 $\mu \mathrm{m}$ de alto x 5-10 $\mu \mathrm{m}$ de ancho.

Hábitat: se encuentra en zonas arenosas, sobre rocas o corales muertos.

\section{Familia Pseudanabaenaceae \\ Pseudanabaena sp. (Fig. 38)}

Tricomas muy largos o cortos que se pueden encontrar solitarios o en grupo, poseen células cilíndricas de coloración verde. Célula terminal redondeada. Vaina ausente. Dimensiones: $1.6 \mu \mathrm{m}(1.3-2.0) \mathrm{x}$ $2.7 \mu \mathrm{m}(2.3-3.3)$.

Hábitat: se encuentra mezclada entre otras cianobacterias epifitas.
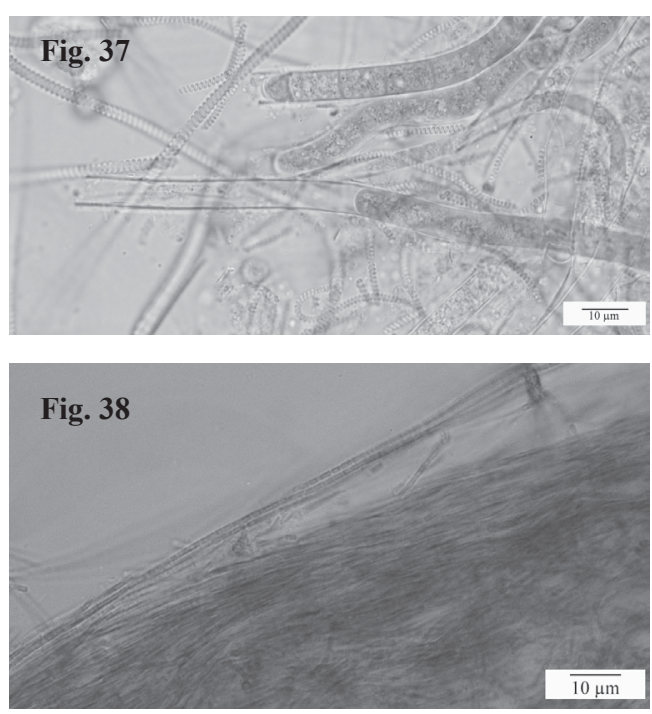

Figs. 35-38. 35. Symploca cf furnicularis. Detalle del filamento y célula apical. 36 y 37. Symploca hydnoides. 36. Aspecto de la colonia. 37. Detalle de los filamentos, vaina y célula apical. 38. Pseudanabaena sp. Aspecto del tricoma

Figs. 35-38. 35. Symploca cf furnicularis. Detail of the filament and apical cell. 36 \& 37. Symploca hydnoides. 36. General view of the colony. 37. Detail of the filaments, sheath and apical cell. 38. Pseudanabaena sp. Appearance of trichome 


\section{Spirulina sp. (Fig. 39)}

Tricomas móviles espiralados de forma regular, ápices redondeados y dirigidos hacia la derecha o la izquierda según la especie. Coloración verde azulada o morada.

Hábitat: se encuentra en casi todos los hábitats posibles pero parece preferir los fondos limo-arcillosos, también se encuentra entre otras cianobacterias. Común en los medios enriquecidos.

\section{Orden Nostocales \\ Familia Nostocacea}

Nodularia harveyana

Thuret ex Bornet et Flahault 1888. Ann. Sci. Nat. Bot., ser. VII, 7: 243. (Figs. 40 y 41)

Filamentos libres, con una coloración verde oliva. Los filamentos y los tricomas son isopolares, con heterocistos intercalares comprimidos. Células más anchas que largas. Dimensiones celulares: $6.9 \mu \mathrm{m}$ (6.3-7.7) x $4.1 \mu \mathrm{m}(3.1-4.5)$.

Hábitat: se encuentra sobre macroalga roja. No identificada.

\section{Familia Rivulariaceae}

\section{Calothrix sp. (Fig. 42)}

Filamentos cortos, con heterocisto basal de $5.2 \mu \mathrm{m}$ de diámetro. Filamento se estrecha hacia el extremo opuesto al heterocisto hasta un ancho muy fino que da la apariencia filiforme.

Hábitat: se encuentra sobre fondos de arena fina en conjunto con $P$. corium y O. limosa.

\section{DISCUSIÓN}

La composición de géneros de cianobacterias encontradas en la costa del Caribe de Costa Rica es muy semejante a la reportada en países como Brasil (Sant'Anna et al. 1985; Sant'Anna \&
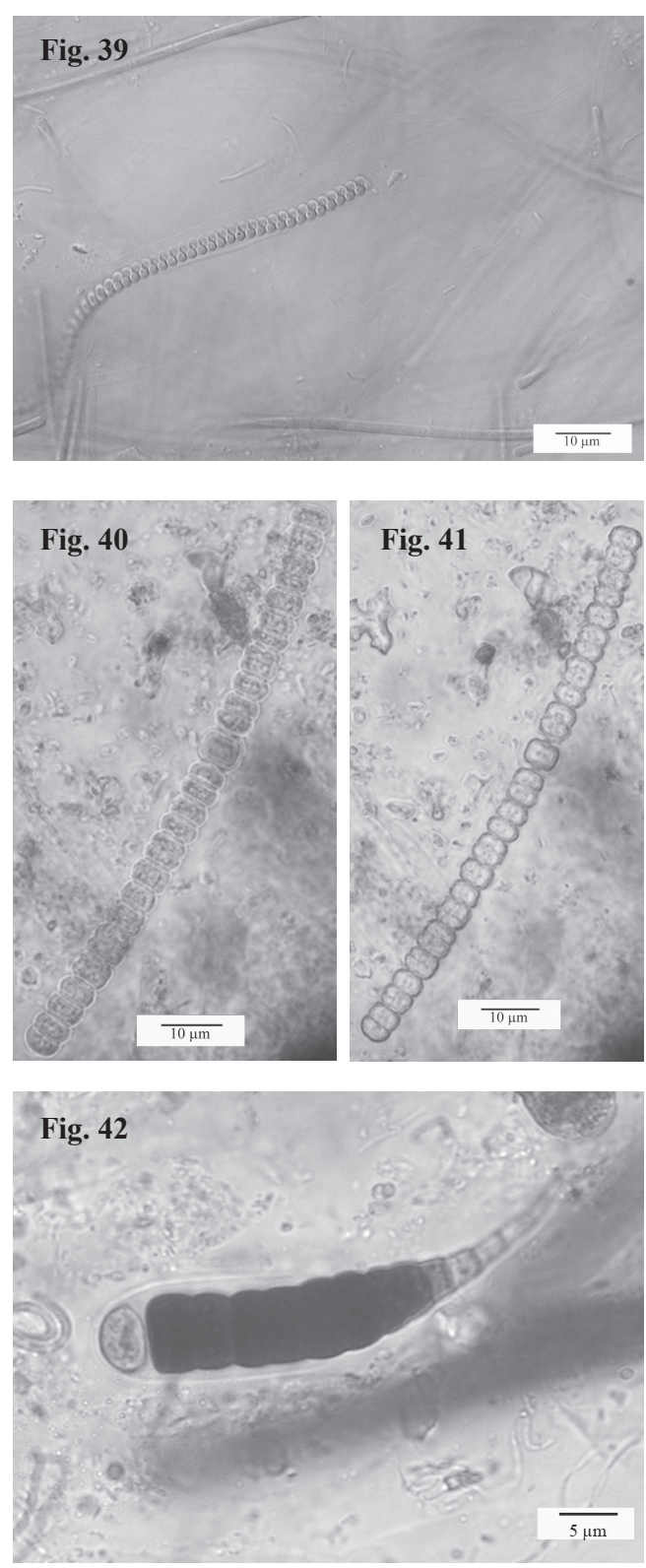

Figs. 39-42. 39. Spirulina sp. Apariencia de los tricomas. 40 y 41. Nodularia harveyana. 40. Aspecto general del filamento. 41. Detalle del heterocisto y su forma comprimida. 42. Calothrix sp. Detalle del filamento

Figs. 39-42. 39. Spirulina sp. Appearance of trichomes. 40 \& 41. Nodularia harveyana. 40. General appearance of the filament. 41. Detail of the heterocist and its compressed form. 42. Calothrix sp. Details of the filament 
Simonetti, 1992; Sant'Anna et al. 2004; Crispino \& Sant'Anna, 2006) y Argentina (Da Rodda \& Parodi, 2005), sin embargo, se pueden encontrar algunas diferencias en relación con la especie. El número de Chroococcales es más bajo al reportado por Crispino \& Sant'Anna (2006), esta diferencia puede deberse a la metodología utilizada, ya que no se tomaron muestras de macroalgas para evaluar la presencia de especies epifitas y a que el muestreo se limitó exclusivamente a la zona sublitoral. La cantidad de Oscillatoriales es mayor y se encontraron géneros que no han sido informados por los autores anteriores, ejemplo de ello son: Leptolyngbya, Pseudanabaena y Borzia. Estos géneros han sido informados en las costas de Suráfrica por Silva \& Pienaar (2000) y en España por Gorostiaga et al. (2004), solo el género Leptolyngbya reporta más de 40 especies que debido a su pequeño tamaño son difíciles de estudiar, Leptolyngbya es común en el Caribe costarricense y se requiere mayor información taxonómica para poder identificarlo a nivel de especie.

Muchas de las especies identificadas son cosmopolitas (Lyngbya aestuarii, Lyngbya confervoides, Coleofasciculus chtonoplastes y Johannesbaptistia pellucida), estas pueden encontrarse en una amplia diversidad de ambientes, incluso los dulceacuícolas. La gran adaptabilidad de las cianobacterias les permite colonizar nichos donde las condiciones varían de manera constante y el medio ambiente marino es un ejemplo de ello. Si bien las cianobacterias están adaptadas a cambios en el medio, las especies bentónicas de la costa del Caribe parecieran ser particularmente susceptibles a cambios en la penetración de la luz y a la acción de las corrientes que mezclan en forma constante el sedimento marino. Muchas especies como $S$. hydnoides que pueden fijarse a sustratos firmes son afectadas por las corrientes y las olas, sus penachos tienden a disminuir de tamaño y se abren, pueden incluso ser desprendidos del bentos cuando el nivel del mar es elevado y existe oleaje fuerte, bajo estas condiciones no se encuentran colonias de cianobacterias en el bentos y la situación de muestreo se dificulta. El mar Caribe se caracteriza por presentar cambios rápidos en los escenarios ambientales, así durante la época lluviosa es posible encontrar períodos de "ventana", donde el entorno es apto para el crecimiento de las poblaciones de cianobacterias. La situación anteriormente expuesta puede explicar por qué la diversidad de estos microorganismos puede ser menor durante la marcada estación lluviosa del Caribe y se incrementa durante los meses sin lluvia de una estación seca poco definida.

Las especies $L$. majuscula y $L$. confervoides son bastante abundantes en Isla Uvita y Piuta durante los meses de menor precipitación, en especial cuando la columna de agua es clara y cuando el mar presenta poco oleaje. En estos sitios, las colonias pueden adquirir tamaños excepcionalmente grandes, y se adhieren sobre cualquier sustrato posible: coral, rocas o macroalgas. Ambas especies han sido asociadas con ambientes alterados (Paul et al. 2005) y con la producción de una serie de metabolitos secundarios utilizados en la defensa contra la herbivoría (Kuffner et al. 2006; Tong \& $\mathrm{Pi}, 2009$ ), por lo que sería recomendable mantener un programa de monitoreo sobre las poblaciones de estos microorganismos, principalmente en Isla Uvita, un sitio turístico que mantiene importantes poblaciones de coral. 


\section{CONCLUSIONES}

Las poblaciones de cianobacterias bénticas marinas en la costa del Caribe costarricense son más abundantes durante los meses en que las precipitaciones disminuyen, especialmente cuando se presentan días soleados, con aguas claras y suave oleaje.

Las especies descritas en este trabajo constituyen un primer reporte para Costa Rica y hacen patente la necesidad de ahondar en esta área de investigación.

\section{BIBLIOGRAFÍA}

Bandyopadhyay, A., Mali, S. M., Lunawat, P., Raja, K. M. \& Gopi, H. N. (2011). Synthesis and Structural Investigations of Functionalizable Hybrid $\beta$-Hairpin. Org. Lett., 13(17), 4482-4485.

Boone, D. R., Castenholz, R. W. \& Garrity, G. M. (eds.) (2001). Bergey's Manual of Systematic Bacteriology. En D. R. Boone, R. W. Castenholz \& G. M. Garrity (Eds.), Vol. 1 The Archaea and the deeply branching and phototrophic Bacteria (473-599). New York, EE.UU.: Springer.

Conroy, T., Guo, J. T., Hunt, N. H. \& Payne, R. J. (2010). Total Synthesis and Antimalarial Activity of Symplostatin 4. Org. Lett., 12(23), 5576-5579.

Crispino, L. M. \& Sant'Anna, C. L. (2006). Cianobactérias marinhas bentônicas de ilhas costeiras do Estado de São Paulo, Brasil. Rev. Brasil. Bot., 29(4), 639-656.

Cronberg, G. \& Annadotter, H. (2006). Manual on aquatic cyanobacteria. A photo guide and a synopsis of their toxicology. Copenhague, Dinamarca: ISSHA \& IOC of UNESCO.
Da Rodda, C. \& Parodi, E. R. (2005). Cyanophyceae Epipelágicas de la Marisma "El Cangrejal" en el estuario de Bahía Blanca (Buenos Aires, Argentina). Bol. Soc. Argent. Bot., 40(3-4), 157-168.

Desikachary, T. V. (1959). Cyanophyta. New Delhi, India: Indian Council of Agricultural Research, Monographs on Algae.

González, L. (1970). Las cianofíceas de Costa Rica. O'Bios. Rev. Cienc. Nat., 2(4), 5-45.

Gorostiaga, J. M., Santolaria, A., Secilla, A., Casares, C. \& Díez, I. (2004). Check-list of the Basque coast benthic algae (North of Spain). An. Jard. Bot. Madrid, 61(2), 155-180.

Komárek, J. \& Anagnostidis, K. (1989). Modern approach to the classification system of Cyanophytes 4 - Nostocales. Arch. Hydrobiol., 56, Sup., (82/3), 247-345.

Komárek, J. \& Anagnostidis, K. (1999). Cyanoprokaryota: 1. Teil: Chroococcales. Jena, Alemania: Gustav Fischer Verlag, Stuttgart.

Komárek, J. \& Anagnostidis, K. (2005). Cyanoprokaryota II. Teil Oscillatoriales. Jena, Alemania: Elsevier/Spektrum Gmbh.

Kuffner, B. L., Walters, L. J., Becerro, M. A., Paul, V. J., Williams-Ritson, R. \& Beach, K. S. (2006). Inhibition of coral recruitment by macroalgae and cyanobacteria. Mar. Ecol. Prog. Ser., 323, 107-117.

Lee, R. E. (1999). Phycology. ( ${ }^{\text {rd }}$. ed.). Edimburgo, Inglaterra: Cambridge University Press.

Linington, R. G., Clark, B. R., Trimble, E. E., Almanza, A., Ureña, L.-D., Kyle, D. E. \& Gerwic, W. H. (2009). Antimalarial Peptides from Marine Cyanobacteria: Isolation and Structural Elucidation of Gallinamide A. J. Nat. Prod., 72(1), 14-17. 
Mian, P., Heilmann, J., Bürgi, H.-R. \& Sticher, O. (2003). Biological screening of Terrestrial and Freshwater Cyanobacteria for Antimicrobial Activity, Brine Shrimp Lethality, and Cytotoxicity. Pharm. Biol., 41(4), 243-247.

Paul, V. J., Thacker, R. W., Banks, K. \& Golubic, S. (2005). Benthic cyanobacterial bloom impacts the reefs of South Florida (Broward County, USA). Coral Reefs, 24(4), 693-697.

Peinador, M. (1992). Cianobacterias potencialmente tóxicas en plantas de tratamiento de aguas en Costa Rica. Rev. Biol. Trop., 42(1/2), 5-8.

Peinador, M. (1999). Las cianobacterias como indicadores de contaminación orgánica. Rev. Biol. Trop., 47(3), 381-391.

Rojas, A. (2004). Aislamiento e identificación de cianobacterias en aguas termales de origen volcánico, volcán Miravalles, Costa Rica. Trabajo final de graduación no publicado. Escuela de Microbiología. Universidad de Costa Rica.

Sant'Anna, C. L., Cordeiro-Marino, M., Braga, M. R. A. \& Guimarães, S. M. P. B. (1985). Cianofíceas marinhas bentônicas das praias de Peruíbe e dos Sonhos, município de Itanhaém, SP, Brasil, 1. Rickia., 12, 89-112.

Sant'Anna, C. L. \& Simonetti, C. (1992). Cianofíceas marinhas bentônicas das Praias de Peruíbe e dos Sonhos, município de Itanhaém, SP, II: espécies epilíticas e epizóicas. Rev. Brasil. Bot., 52(3), 515-528.

Sant'Anna, C. L., Azebedo, M. P., Senna, A. P., Komárek, J. \& Komárková, J. (2004). Planktic Cyanobacteria from São Paulo State, Brazil: Chroococcales. Rev. Brasil. Bot., 27(2), 213-227.
Silva, S. M. F. \& Pienaar, R. N. (2000). Benthic Marine Cyanophyceae from Kwa-Zulu Natal, South Africa. Berlín, Germany: J. Cramer, Stuttgart.

Soltani, N., Khavari-Nejad, R. A., Yazdi, M. T., Shokravi, Sh. \& FernándezValiente, E. (2005). Screening of Soil Cyanobacteria for Antifungal and Antibacterial Activity. Pharm. Biol., 43(5), 455-459.

Tong, T. L. \& Pi, B. (2009). Chemical ecology of marine cyanobacterial secondary metabolites: a mini-review. $J$. Coastal Dev., 13(1), 1-8.

Tripathi, A., Puddick, J., Prinsep, M. R., Rottmann, M. \& Tan, L. T. (2010). Lagunamides A and B: Cytotoxic and antimalarial Cyclodepsipeptides from the Marine cyanobacterium Lyngbya majuscula. J. Nat. Prod., 73(11), 1810-1814.

Vargas-Montero, M. \& Freer, E. (2004). Proliferaciones algales nocivas de cianobacterias (Oscillatoriaceae) y dinoflagelados (Gymnodiniaceae) en el Golfo de Nicoya, Costa Rica. Rev. Biol. Trop., 52(1), 121-125.

Wehr, J. D. \& Sheath, R. G. (2002). Freshwather Algae of North America: Ecology and classification. San Diego, CA, EE.UU.: Academic Press.

Whitton, B. A. \& Potts, M. (2000). The ecology of cyanobacteria. Their diversity in time and space. En B. A. Whitton \& M. Potts (Eds.), Introduction to the Cyanobacteria (pp. 1-10). New York, EE.UU.: Kluwer Academic Publishers.

Woese, C. R., Kandler, O. \& Wheelis, M. L. (1990). Towards a natural system of organisms: proposal for the domains Archaea, Bacteria, and Eucarya. Proc. Natl. Acad. Sci. USA., 87(12), 4576-4579. 